\title{
Retinopathy and retinal function in insulin-dependent diabetes mellitus
}

\author{
JANE MOLONEY ${ }^{1}$ AND MICHAEL IVO DRURY ${ }^{2}$ \\ From the 'Royal Victoria Eye and Ear Hospital and the ${ }^{2}$ Mater Miscericordiae Hospital, Dublin
}

SUMMARY Sixty-six insulin-dependent diabetic patients with normal visual acuity were studied (132 eyes). The mean age was 27.7 years with a mean duration of diabetes mellitus of 8.7 years. Their mean electro-oculogram ratio, Arden grating and Munsell-Farnsworth scores were markedly abnormal $(p \ll 0 \cdot 00001)$. Background retinopathy was present in 53 eyes $(40 \cdot 2 \%)$, abnormal Arden grating scores (greater than 82 ) in 70 eyes (53\%), abnormal Farnsworth-Munsell 100-hue score (greater than 100$)$ in 88 eyes $(56.7 \%)$, and 29 eyes (22\%) had an electro-oculogram ratio less than 160. These abnormalities of retinal function did not correlate with retinopathy and were not secondary to it. Smoking caused a significant deterioration in contrast sensitivity.

There are abnormalities of retinal colour, form, and light sense in diabetes. These abnormalities may antedate retinopathy.

Bronte-Stewart et al. ${ }^{1}$ assessed colour vision in 54 childhood diabetics over a 4-year period. No deterioration in colour sense was found by the Farnsworth-Munsell 100-hue test. A further report ${ }^{2}$ on these patients at $\mathbf{1 0}$ years showed the gradual appearance of yellow-blue defects, which in some cases preceded the development of retinopathy.

Kinnear et al. $^{3}$ studied colour vision in 800 diabetics. With the 100-hue test the mean error score in patients without retinopathy was significantly greater than normal. There was a further increase in the error score in diabetics with retinopathy. This increase was statistically significant only in patients over 30 years of age. They found that changes in the 100-hue test were of no value in predicting the development of retinopathy.

Arden ${ }^{4}$ found no abnormality in contrast sensitivity in 18 diabetic patients without retinopathy. Of 47 patients with retinopathy and normal visual acuity over $50 \%$ had abnormal grating scores. Foulds and McClure $^{2}$ found the mean grating score was significantly greater than normal in 12 diabetic patients without retinopathy. The increase was apparent on all plates.

Correspondence to Dr J. B. M. Moloney, Research Foundation, Royal Victoria Eye and Ear Hospital, Adelaide Road, Dublin 2. Ireland.
Baiteryakova et al. ${ }^{5}$ studied 60 diabetic patients and showed a reduction in the electro-oculogram which could be present before the development of retinopathy. These findings were confirmed by Flicker ${ }^{6}$ in his study of 93 diabetic patients.

To decide the role of retinal function tests in the assessment of diabetic retinopathy we carried out tests of retinal form, colour, and light sense on 132 eyes with normal visual acuity in 66 female insulindependent diabetics aged between 20 and 40 years.

\section{Patients and methods}

Sixty-six female well controlled insulin-dependent diabetic patients with normal corrected visual acuity were assessed. They had a full ophthalmological examination, including retinal photography and fluorescein angiography. The mean age was $27 \cdot 7$ years, SEM 0.4 year. The mean duration of diabetes mellitus was 8.7 years, SEM 0.5 year. The mean insulin dose was 43.6 international units, SEM 1.2. Twenty-four (36.4\%) were smokers and $10(15.2 \%)$ were taking anovulants.

Retinal contrast sensitivity was determined with a book of Arden gratings ${ }^{7}$ under standard daylight illumination in a Veri Vide cabinet. A total score greater than 82 was taken as abnormal.

Colour discrimination was tested by the Farnsworth-Munsell 100 -hue test ${ }^{8}$ under the same conditions. A total score greater than 100 was taken as abnormal. 


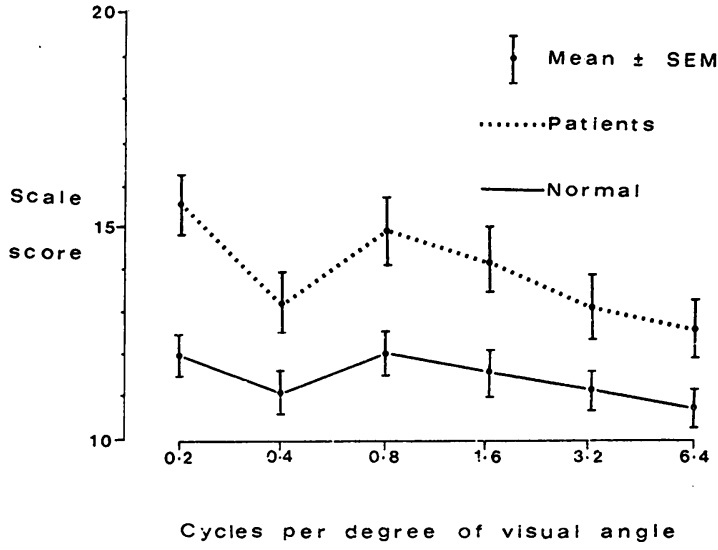

Fig. 1 The mean scale score for each spatial frequency of the Arden grating score book, as recorded in normal subjects and diabetic patients. The mean score is significantly greater in the diabetic patients at all frequencies. The diabetic profile is similar to the normal profile.

Finally, retinal light sense was determined by an electro-oculogram by the technique described by Arden et al. ${ }^{9}$ A ratio less than 160 was taken as abnormal. These 3 tests are objective, reproducible, and assign a definite score to each aspect of retinal function.

\section{Results}

Background retinopathy was found in $53(40 \cdot 2 \%)$ eyes. No patient had proliferative retinopathy. Duration of diabetes was significantly correlated with retinopathy. The mean duration in patients with retinopathy was 11.4 years, SEM 0.7 year, compared with 6.9 years, SEM 0.6 years $(\mathrm{p} \ll 0 \cdot 00001)$ in those without retinopathy.

Contrast sensitivity. The mean total grating score in the 132 eyes was 81.9 , SEM $1 \cdot 4$, compared to a normal mean for our clinic of 68 , SEM $1 \cdot 1$ $(\mathrm{p} \mid \ll 0 \cdot 00001)$. An increased score was apparent on all plates (Fig. 1). Seventy (53\%) of the eyes had an abnormal grating score. The mean grating score and the prevalence of abnormal grating scores were similar in patients with and without retinopathy (Table 1). Mean grating scores and the prevalence of abnormal grating scores did not correlate with age or duration of diabetes. There was, however, a surprisingly strong correlation with smoking practice (Table 2).

Colour discrimination. The mean 100-hue score in 132 eyes was $138 \cdot 7$, SEM 7.7, compared with a normal score in our clinic of 60, SEM 2.0 $(\mathrm{p} i \ll 0 \cdot 00001)$. In all 88 eyes $(66 \cdot 7 \%)$ had a score of greater than 100.
Table 1 Retinopathy and retinal function tests

\begin{tabular}{lccc}
\hline & $\begin{array}{l}\text { Retinopathy } \\
\text { (53) }\end{array}$ & $\begin{array}{l}\text { No } \\
\text { retinopathy } \\
(79)\end{array}$ & p value \\
\hline Mean grating score & $80 \cdot 2$ & $83 \cdot 2$ & $\mathrm{NS}^{*}$ \\
Grating score $>82$ & $24(45 \cdot 3 \%)$ & $46(58 \cdot 2 \%)$ & $\mathrm{NS}^{\dagger}$ \\
Mean 100-hue score & $121 \cdot 2$ & $150 \cdot 3$ & $\mathrm{NS}^{*}$ \\
100-hue score $>100$ & $40(75 \cdot 5 \%)$ & $48(60 \cdot 8 \%)$ & $\mathrm{NS}^{\dagger}$ \\
Mean EOG ratio & $180 \cdot 9$ & $190 \cdot 2$ & $\mathrm{NS}^{*}$ \\
EOG <160 & $13(24 \cdot 5 \%)$ & $16(20 \cdot 3 \%)$ & $\mathrm{NS} \dagger$ \\
\hline
\end{tabular}

*Mann-Whitney U-Wilcoxon rank sum W test.

†Chi-square test.

Table 2 Smoking and contrast sensitivity in diabetes

\begin{tabular}{llll}
\hline & Smokers (48) & $\begin{array}{l}\text { Nonsmokers } \\
(84)\end{array}$ & $p$ value \\
\hline Mean grating score & $90 \cdot 7$ & $76 \cdot 9$ & $0 \cdot 005^{*}$ \\
Grating score $>82$ & $33(66 \cdot 8 \%)$ & $37(44 \cdot 0 \%)$ & $0 \cdot 01^{\dagger}$ \\
\hline
\end{tabular}

*Mann-Whitney U-Wilcoxon rank sum W test (2 tail).

tChi-square test (1 tail).

Table 3 Prevalence of abnormalities in 100-hue and grating scores related to the EOG ratio

\begin{tabular}{lll}
\hline & 100 -hue $>100$ & Grating score $>82$ \\
\hline EOG $<160(29)$ & $21(72 \cdot 4 \%)$ & $17(58 \cdot 6 \%)$ \\
EOG $\geq 160(103)$ & $67(65 \cdot 0 \%)$ & $53(51 \cdot 5 \%)$ \\
p value $^{*}$ & NS & NS \\
\hline
\end{tabular}

*Chi-square test.

Table 4 Prevalence of abnormalities in 100-hue score and EOG ratio related to grating score

\begin{tabular}{lll}
\hline & EOG $<160$ & 100 -hue $>100$ \\
\hline Grating score $>82(70)$ & $17(24 \cdot 3 \%)$ & $54(77 \cdot 1 \%)$ \\
Grating score $\leq 82(62)$ & $12(19 \cdot 4 \%)$ & $34(54 \cdot 8 \%)$ \\
p value & NS & $<0.01$ \\
\hline
\end{tabular}

*Chi-square test (1 tail).

Table 5 Prevalence of abnormalities in EOG ratio and grating score related to 100-hue score

\begin{tabular}{lcl}
\hline & $E O G<160$ & Grating $>82$ \\
\hline 100 -hue score $>100(88)$ & $: 21(23.9 \%)$ & $54(61 \cdot 4 \%)$ \\
100 -hue score $\leq 100(44)$ & $8(18 \cdot 2 \%)$ & $16(36.4 \%)$ \\
p value* & NS & $<0.01$ \\
\hline
\end{tabular}

*Chi-square test (1 tail).

Retinopathy showed no significant correlation with the mean 100-hue score or the prevalence of abnormal 100-hue scores (Table 1). Neither the mean 100-hue score nor the prevalence of abnormal scores showed any correlation with age, duration of diabetes, or the use of anovulants. 
Light sense. The mean EOG ratio in the 132 eyes was $186 \cdot 5$, SEM $2 \cdot 8$, compared with normal ratio in our clinic of 233 , SEM $1 \cdot 8(\mathrm{p} \ll 0 \cdot 00001)$. Twenty-nine $(22 \%)$ of the eyes had a ratio below 160 .

Retinopathy showed no significant correlation with mean EOG ratio or the prevalence of abnormal ratios (Table 1). The mean EOG ratio and the prevalence of abnormal EOG ratios correlated with duration of diabetes. The score correlation was $r=-0.17$ $(p<0.05)$. The mean duration of diabetes in 29 eyes with abnormal EOGs was $11 \cdot 2$ years, SEM $1 \cdot 1$ years, compared with $8 \cdot 9$, SEM $0 \cdot 5$, in the eyes with normal light sense $(p<0 \cdot 01)$. There was no correlation with age.

Abnormalities in the EOG ratio were not predictive for abnormalities in Farnsworth-Munsell or grating scores (Table 3).

Eyes with abnormal grating scores were more likely to have an abnormal Farnsworth-Munsell (100-hue test) and vice versa (Tables 4 and 5).

\section{Discussion}

In the group of young diabetic patients studied retinal light form and colour sense were severely and significantly reduced in comparison with the normal population. The prevalence of these functional changes exceeds the prevalence of retinopathy, and in fact only $7(10.6 \%)$ of the 66 patients studied had normal retinal function in both eyes. These functional changes are not secondary to retinal microvascular change, as in 79 eyes with normal retinas the EOG was abnormal in $20 \%$, contrast sensitivity was abnormal in $44 \%$, and hue discrimination in $60 \%$.

These changes cannot predict the development of retinopathy, as they show no correlation with retinopathy. Kinnear et al. ${ }^{3}$ showed a correlation between abnormalities in the 100 -hue test scores and retinopathy; this was in a mixed group of diabetics, and the correlation was only in older patients. In the very young patients reported on by Bronte-Stewart $e t$ $a l .^{\prime}$ few had either retinopathy or abnormalities in function tests. However, in the patients aged 20-40 reported on here retinopathy and retinal function abnormalities are appearing, and at this stage there is no correlation between retinal function and retinopathy. In older patients with established retinopathy the microvascular changes might cause a further deterioration in retinal function.

Abnormalities of retinal function may represent an independent manifestation of diabetic eye disease unrelated to vascular change. Hue and contrast discrimination correlate with each other and may share a common aetiology. Changes in the electrooculogram correlate with duration of diabetes mellitus but show no correlation either with retinopathy or with other tests of retinal function. This may also be a further independent manifestation of diabetic eye disease.

Smoking is associated with a further significant deterioration in contrast sensitivity in diabetic patients.

J.M. was supported by a grant from the Medical Research Council of Ireland.

\section{References}

1 Bronte-Stewart JM, Cant JS, Craig JO. The detection of early visual loss in young diabetics. Proc $R$ Soc Med 1970; 63: 786-8.

2 Foulds WS, McClure E. The assessment of visual function with particular reference to vascular disease of the eye. Trans Ophthalmol Soc NZ 1980; 32: 55-68.

3 Kinnear PR, Aspinall PA. Lakawski R. The diabetic eye and colour vision. Trans Ophthalmol Soc UK 1972; 92: 69-78.

4 Arden GB. Visual loss in patients with normal visual acuity. Trans Ophthalmol Soc UK 1978; 98: 219-31.

5 Baiteryakova LS, Mironova EM, Eskin VY. Electro-oculographic study in patients with diabetes mellitus. Vestn Oftalmol 1976; 92: 69-71.

6 Flicker FM. Electrophysiological examinations in the early diagnosis of diabetic retinopathy and evaluation of its clinical course. Vestn Oftalmol 1980; 97: 45-7.

7 Arden GB. The importance of measuring contrast sensitivity in cases of visual disturbance. Br J Ophthalmol 1978; 62: 198-209.

8 Farnsworth D. The Farnsworth-Munsell 100 hue and dichomatous tests for colour vision. J Opt Soc Am 1943; 33: 568-78.

9 Arden GB. Barrada A, Kelsey JH. New clinical test of retinal function based on the standing potential of the eye. $\mathrm{Br} J$ Ophthalmol 1962; 46: 449-67. 